\title{
Distinct potential aerosol masses under different scenarios of transport at a suburban site of Beijing
}

\author{
Biwu Chu ${ }^{1}$, Yongchun Liu ${ }^{1}$, Qingxin $\mathrm{Ma}^{1}$, Jinzhu $\mathrm{Ma}^{1}$, Hong $\mathrm{He}^{1, *}$, Gang Wang ${ }^{2}$, \\ Shuiyuan Cheng ${ }^{2}$, Xinming Wang ${ }^{3}$ \\ 1. State Key Joint Laboratory of Environmental Simulation and Pollution Control, Research Center for Eco-Environmental Sciences, \\ Chinese Academy of Sciences, Beijing 100085, China. E-mail: bwchu@rcees.ac.cn \\ 2. Key Laboratory of Beijing on Regional Air Pollution Control, Beijing University of Technology, Beijing 100022, China \\ 3. State Key Laboratory of Organic Geochemistry, Guangzhou Institute of Geochemistry, Chinese Academy of Sciences, Guangzhou 510640, \\ China
}

\section{A R T I C L E I N F O}

Article history:

Received 20 August 2015

Revised 7 November 2015

Accepted 11 November 2015

Available online 8 December 2015

Keywords:

Potential aerosol mass

Local emission

Long distance transport

Aging

In situ perturbation experiments

\begin{abstract}
A B S T R A C T
In order to evaluate the secondary aerosol formation potential at a suburban site of Beijing, in situ perturbation experiments in a potential aerosol mass (PAM) reactor were carried out in the winter of 2014. The variations of secondary aerosol formation as a function of time, $\mathrm{OH}$ exposure, and the concentrations of gas phase pollutants and particles were reported in this study. Two periods with distinct secondary aerosol formation potentials, marked as Period I and Period II, were identified during the observation. In Period I, the secondary aerosol formation potential was high, and correlated well to the air pollutants, i.e., $\mathrm{SO}_{2}, \mathrm{NO}_{2}$, and CO. The maximal secondary aerosol formation was observed with an aging time equivalent to about 3 days of atmospheric oxidation. In period II, the secondary aerosol formation potential was low, with no obvious correlation with the air pollutants. Meanwhile, the aerosol mass decreased, instead of showing a peak, with increasing aging time. Backward trajectory analysis during the two periods confirmed that the air mass in Period I was mainly from local sources, while it was attributed mostly to long distance transport in Period II. The air lost its reactivity during the long transport and the particles became highly aged, resulting in a low secondary aerosol formation potential. Our experimental results indicated that the in situ measurement of the secondary aerosol formation potential could provide important information for evaluating the contributions of local emission and long distance transport to the aerosol pollution.
\end{abstract}

(C) 2015 The Research Center for Eco-Environmental Sciences, Chinese Academy of Sciences. Published by Elsevier B.V.

\section{Introduction}

Haze has increased in frequency in megacities in China in recent years. The fine particulate matter $\left(\mathrm{PM}_{2.5}\right)$, the main cause of the haze, is mainly contributed by secondary aerosol formation during atmospheric reactions. Sulfate, nitrate, and ammonium (SNA) contribute $40 \%-60 \%$ of $\mathrm{PM}_{2.5}$ mass in China
(Yang et al., 2011; Zhao et al., 2013a), and the majority of the organic mass in $\mathrm{PM}_{2.5}$ is generated by secondary reactions rather than being emitted directly from pollution sources (Dan et al., 2004; Duan et al., 2005; Wang et al., 2012). Secondary aerosols are produced during the continuous oxidation of gaseous emissions. The secondary aerosol formation potential of the air is essential for understanding the origins of the

\footnotetext{
* Corresponding author. E-mail: honghe@rcees.ac.cn (Hong He).
} 
secondary aerosols and predicting their impacts on haze pollution. High growth rates of secondary species and high number concentrations of particles were frequently observed during heavy haze pollution in Beijing (He et al., 2014; Jiang et al., 2015; Liu et al., 2013; Sun et al., 2014; Wang et al., 2014c; Zheng et al., 2015), indicating a high secondary aerosol formation potential of the air. Most of the related studies on the aerosol pollution in Beijing have focused on the chemical composition or the seasonal variations and sources of $\mathrm{PM}_{2.5}$ (Guo et al., 2014; He et al., 2001; Wang et al., 2015). A recent trend in atmospheric chemistry is to perform in situ perturbation experiments (Farmer and Jimenez, 2010), which have been used to quantify secondary aerosol production from the emission of biomass burning (Keller and Burtscher, 2012; Ortega et al., 2013) and vehicles (Tkacik et al., 2014). As far as we know, no in situ investigation on the secondary aerosol formation potential of ambient air in Beijing has been reported.

Transformation of precursors to secondary aerosol and the regional transport of pollutants from upwind regions were considered to be the two main reasons for the high concentration of particles during heavy haze episodes in Beijing (Guo et al., 2014; He et al., 2014; Wang et al., 2014a; Zhao et al., 2013a,2013b). However, it is hard to quantify the relative importance of these factors, which is crucial for understanding the formation mechanism and developing control strategies for the severe haze in the winter of Beijing. What's more, transformation and transport of pollutants occurs simultaneously, complicating this further. Current air quality models have usually under-predicted $\mathrm{PM}_{2.5}$ concentrations, especially during heavy haze episodes (Wang et al., 2014b; Zheng et al., 2014). Investigation of the secondary aerosol formation potential of air may provide insights for better understanding the transformation and transport of pollutants.

The concept of potential aerosol mass (PAM) was introduced by Kang et al. (2007). PAM indicates the amount of aerosol mass that the oxidation of precursor gases produces. In order to track the fast changes of precursor gases in the atmosphere, all precursor gases were rapidly oxidized with an extreme high concentration of oxidants in a flow tube, which was called a PAM reactor. The oxidation of precursor gas, nucleation, and gas-particle partitioning, which took hours in the atmosphere, was shortened to a few minutes in the PAM reactor. The PAM reactor was used to simulate the formation and aging of aerosols (Chen et al., 2013; Kang et al., 2011; Lambe et al., 2011, 2012), to evaluate of the secondary organic aerosol (SOA) formation potential of source emissions (Keller and Burtscher, 2012; Ortega et al., 2013), and to quantify secondary aerosol production in situ (Farmer and Jimenez, 2010). The PAM results, including particle chemical composition and size distributions, were comparable to those observed in environmental chambers, which have been widely used to simulate secondary aerosol formation (Kang et al., 2007). In typical environmental chambers, the amounts of oxidants are usually similar to those in the atmosphere, with tens or hundreds of ppb of ozone and $10^{5}-10^{7}$ molecules $/ \mathrm{cm}^{3}$ $\mathrm{OH}$ radical. The residence times in chambers are usually several hours, similar to timescales of SOA formation, but shorter than the total aging time in the atmosphere. Chamber experiments also lasted too long to track the rapid changes of precursor gases in the atmosphere, while in situ measurement of PAM has the advantage of fast simulation (Kang et al., 2007), with similar exposure to oxidants in the atmosphere.

In order to evaluate the secondary aerosol formation potential at a suburban site of Beijing, in situ perturbation experiments (exposing the air sample to a high concentration of $\mathrm{OH}$ radicals to perturb the oxidation process) were carried out in a PAM reactor. The variations of secondary aerosol formation as a function of time, $\mathrm{OH}$ exposure, and the concentrations of gas phase pollutants and particles are reported in this study. The PAMs under different scenarios of transport are discussed.

\section{Methods}

\subsection{PAM flow reactor}

The PAM flow reactor was constructed following the design of Kang et al. (2007). Twin PAM flow reactors were used in this study. Each PAM flow reactor is a steel cylinder coated with Teflon FEP film ( $0.5 \mathrm{~mm}$ thick). The structure of the PAM flow reactor is displayed in Fig. 1a. The volume of the cylinder reactor is about $15 \mathrm{~L}$, with a length of $50 \mathrm{~cm}$, and a diameter of $20 \mathrm{~cm}$. A mixing tube, with a length of $30 \mathrm{~cm}$ and a diameter of $6 \mathrm{~cm}$, is placed in front of the reactor, allowing the sample gases to be well mixed before reaction. Four UV lamps (ZW20S26W, Beijing Lighting Research Institute, China), which produce mainly $254 \mathrm{~nm}$ light, are mounted in each reactor near the wall. In the observation periods, one PAM flow reactor was running with four lamps on, indicated as the PAM reactor, while the other was running without irradiation, indicated as the bypass reactor. In order to control the temperature of the reactors and the lamps, circulating water and zero air flowed continuously through the jackets around the reactors and the lamps, respectively. The temperature and the relative humidity (RH) in the reactors were measured continuously near the outlet of the reactors. In this study, the temperature of the PAM reactor was in the range of $24-26^{\circ} \mathrm{C}$, while the $\mathrm{RH}$ ranged between $20 \%-30 \%$.

As shown in Fig. 1b, four flows were directed into the reactor, including three flows of zero air carrying ozone, water, and methanol respectively, and a flow of sample ambient air. The three flows of zero air were controlled by mass flow controllers, adding up to about $2.3 \mathrm{~L} / \mathrm{min}$. The sample ambient air was continuously added so that the total volumetric air flow of the reactor was fixed at about $6.9 \mathrm{~L} / \mathrm{min}$, controlled by the mass flow controller before the exhaust pump. At these flow rates, the pollutants in the sample ambient air were diluted to $2 / 3$ of their original concentrations, and the flow in the reactor was calculated to be laminar with a Reynolds number less than 100. The outlets were placed in the center at the end of each PAM flow reactor, and were connected to a three-way electromagnetic valve, which switched the total flow passing through the two reactors. Aerosols and gases were sampled after the electromagnetic valve. $\mathrm{O}_{3}$ was generated by irradiating purified air with $185 \mathrm{~nm}$ UV light (GPH 150T5L/4\& GPH 287T5L/4, UV-TEC Electronics Co., LTD, China) using a home-made $\mathrm{O}_{3}$ generator, without generating $\mathrm{NO}_{x} . \mathrm{OH}$ and $\mathrm{HO}_{2}$ were also generated in the external $\mathrm{O}_{3}$ generator, but essentially all $\mathrm{OH}$ and $\mathrm{HO}_{2}$ were reacted away before they 
a PAM (or bypass) reactor

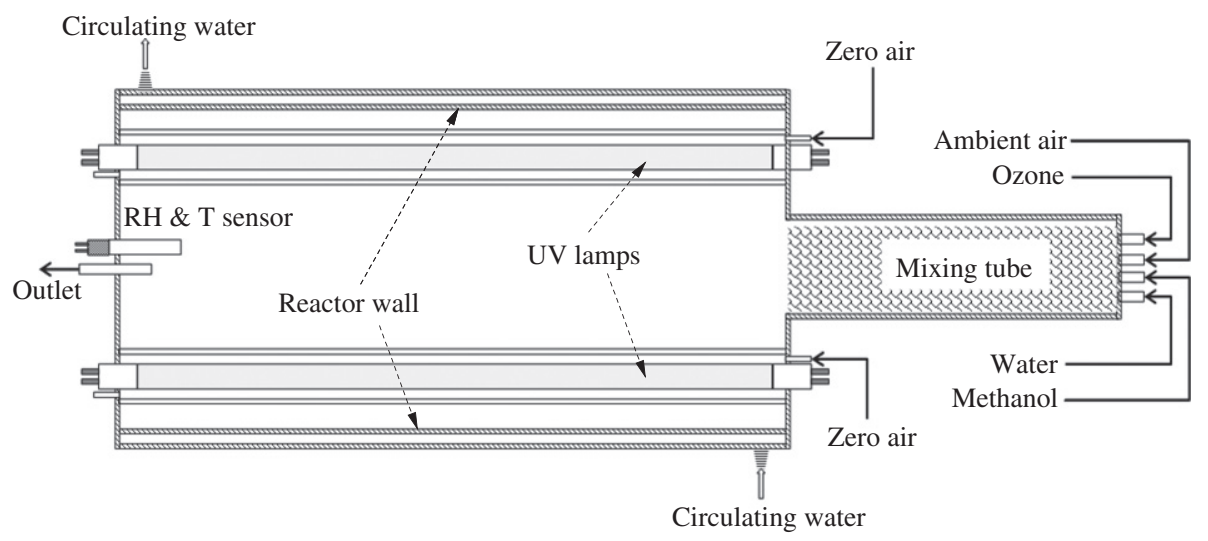

b Experimental system

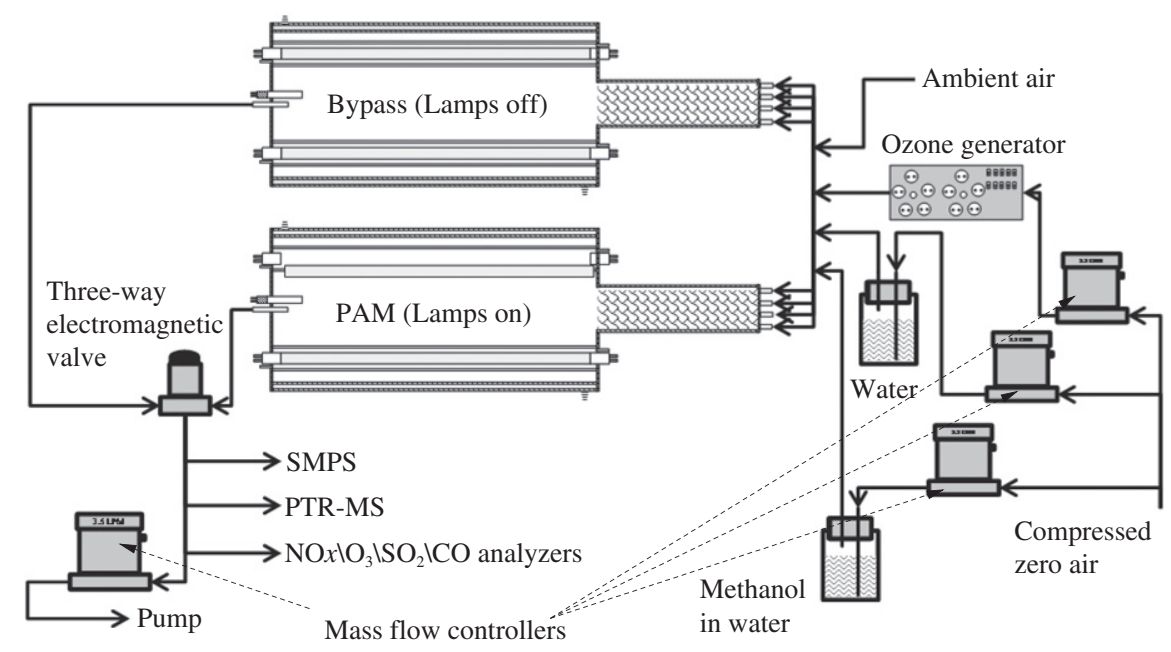

Fig. 1 - PAM flow reactor (a) and the experimental system (b). PAM: potential aerosol mass.

reached the chamber. Different concentrations of $\mathrm{O}_{3}$ were generated by turning on varying numbers of UV lamps.

\subsection{Determination of aging time and PAM}

The concentration of $\mathrm{OH}$ radical in the reactor was mainly controlled by varying the concentration of ozone in the ozone generator. In addition, the $\mathrm{RH}$ in the flow reactor also influences the concentration of $\mathrm{OH}$ radical. Although some humid air was added to the total flow of the reactor, the varying humidity in the ambient air during the observation period also resulted in an inconstant $\mathrm{RH}$, and therefore, a varying concentration of $\mathrm{OH}$ radical in the reactor. To estimate the concentration of $\mathrm{OH}$ radical as well as the aging time equivalent to atmospheric oxidation $\left(T_{a}\right)$ in the reactor, a flow of zero air with methanol was added to the total flow. $T_{a}$ was calculated via Eq. (1):

$\mathrm{T}_{a}=\frac{\ln \frac{\mathrm{C}_{\mathrm{CH}_{3} \mathrm{OH}, \mathrm{O}}}{\mathrm{C}_{\mathrm{CH}_{3} \mathrm{OH}, 1}}}{k_{\mathrm{CH}_{3} \mathrm{OH}, \mathrm{O}+\mathrm{OH}} \times \mathrm{C}_{\mathrm{OH}, \text { air }}}$

where $\mathrm{C}_{\mathrm{CH}_{3} \mathrm{OH}, \mathrm{O}}$ and $\mathrm{C}_{\mathrm{CH}_{3} \mathrm{OH}, 1}$ are the concentrations of methanol in the outlet of the bypass reactor and the PAM reactor, respectively, while $k_{\mathrm{CH}_{3} \mathrm{OH}, \mathrm{O}+\mathrm{OH}}$ is the reaction rate constant of methanol and $\mathrm{OH}$ radical, and $\mathrm{C}_{\mathrm{OH}}$,air is the concentration of $\mathrm{OH}$ radical under typical atmospheric conditions (1.5 $\times$ $10^{6}$ molecule $/ \mathrm{cm}^{3}$ was used in this study).

The concentration of $\mathrm{OH}$ radical in the reactor $\left(\mathrm{C}_{\mathrm{OH}, 1}\right)$ could be estimated similarly in Eq. (2):

$\mathrm{COH}_{\mathrm{OH}}=\frac{\ln \frac{\mathrm{C}_{\mathrm{CH}_{3} \mathrm{OH}, 0}}{\mathrm{C}_{\mathrm{CH}_{3} \mathrm{OH}, 1}}}{k_{\mathrm{CH}_{3} \mathrm{OH}, \mathrm{O}+\mathrm{OH}} \times \mathrm{T}_{\mathrm{r}}}$

where $T_{\mathrm{r}}$ is the residence time of the flow in the reactor, which was about $130 \mathrm{~s}$ in this study.

The PAM of the ambient air sample with preexisting aerosols was estimated according to the concentrations of aerosol in the outlet of the PAM reactor and the bypass reactor. Since the residence time in the reactor was only about $2 \mathrm{~min}$, the wall deposition and particle coagulation in the reactors should not be significant. Although it is hard to quantify the gain or loss of particulate masses due to heterogeneous reactions of preexisting particles in the PAM reactor, the short residence time might also limit its importance in the PAM study compared to the oxidation of gas precursors. Particles 
with diameter larger than $200 \mathrm{~nm}$ were the main contributors to the preexisting particles. There were no obvious changes in the size distributions of these particles in the Bypass and PAM reactors. Particle mass gain in the PAM reactor was mainly due to generation of particles with diameter less than $100 \mathrm{~nm}$. However, particle formation in the introduced zero air should be considered. The aerosol mass formation of zero air $\left(\mathrm{PAM}_{\text {zero air }}\right)$ was measured in a survey experiment when introducing zero air rather than the ambient air sample into the PAM reactor. The value ranged from $0-0.5 \mu \mathrm{g} / \mathrm{m}^{3}$ with aging time equivalent to $0-5$ days of atmospheric oxidation. Then, the mass balance could be written as Eq. (3):

$\mathrm{PAM}_{\text {air }} \times r_{\text {mix }}+\mathrm{PAM}_{\text {zero air }} \times\left(1-r_{\text {mix }}\right)=\mathrm{C}_{\mathrm{PM}, 1}-\mathrm{C}_{\mathrm{PM}, 0}$

where $P A M_{a i r}$ is the PAM of the ambient air sample with preexisting aerosols, $C_{P M, 1}$ and $C_{P M, 0}$ are the concentrations of particles in the outlet of the PAM reactor and the bypass reactor, respectively, and $r_{\text {mix }}$ is the ratio of air sample flow to the total flow, which was $2 / 3$ in this study. Rewriting Eq. (3), (PAM $\left.{ }_{\text {air }}\right)$ was estimated in Eq. (4):

$\mathrm{PAM}_{\text {air }}=\frac{\mathrm{C}_{P M, 1}-C_{P M, 0}}{r_{\operatorname{mix}}}-\mathrm{PAM}_{\text {zero air }} \times \frac{\left(1-r_{\text {mix }}\right)}{r_{\text {mix }}}$.

\subsection{Observation site and period}

The observation site was located in the Yanqi Lake campus of the University of Chinese Academy of Sciences in Huairou district in Beijing $\left(40.4^{\circ} \mathrm{N}, 116.6^{\circ} \mathrm{E}\right)$. As shown in Fig. 2, the campus is about $61 \mathrm{~km}$ northeast of Beijing city center and could be considered as a suburban area. The campus is in the northeast of Yanqi Lake, within $1 \mathrm{~km}$, and about $13 \mathrm{~km}$ to the northwest of Daguang highway. The observation site was on the west side of Jingjia road, with moderate traffic intensity. The PAM reaction system was installed on the 4 th floor of the first classroom building in the campus, which was about $400 \mathrm{~m}$ away from Jingia road.

\section{Results and discussion}

\subsection{Time variation of PAM concentration}

The experiments lasted for about 3 weeks in the winter of 2014, from 5th December to 24th December. The PAM concentrations and the particle concentrations from the PAM and Bypass reactors with size range of 14-750 $\mathrm{nm}$ are displayed in Fig. 3, with the color of the PAM data points indicating the aging time equivalent to atmospheric oxidation. The PAM concentration varied considerably in the observation period. In the first 10 days, from 5th December to 15th December, we observed a consistent change trend of secondary aerosol formation in the PAM reactor as a function of the background particle concentration, regardless of the fact that the aging time was long in the first 3 days but short in the following week. Very serious pollution occurred around 19th December; however, the secondary aerosol formation in the PAM reactor was not significant. The reason for this phenomenon might be a low aging time and a more significant mass loss due to the irradiation in the PAM reactor with the higher concentration of background particles. In the last 5 days of the observation, we increased the ozone concentration, and therefore increased the aging time in the PAM reactor, but no significant secondary aerosol formation was observed, showing entirely different properties compared to the first few days in the observation period. We chose two representative periods for contrastive analysis, as indicated in Fig. 3. The two periods were named "Period I" and "Period II", respectively.

As shown in Fig. 4, in Period I (from 5th to 9th December, 2014), the PAM was high, ranging from $10-60 \mu \mathrm{g} / \mathrm{m}^{3}$, while in Period II (from 19th to 23rd December), the PAM was near zero. Generally speaking, no obvious diurnal variation was observed for the PAM concentration. However, frequent peaks in the PAM concentration were observed during the morning rush hour in Period I, indicating a significant contribution of traffic emissions to secondary aerosol formation at the

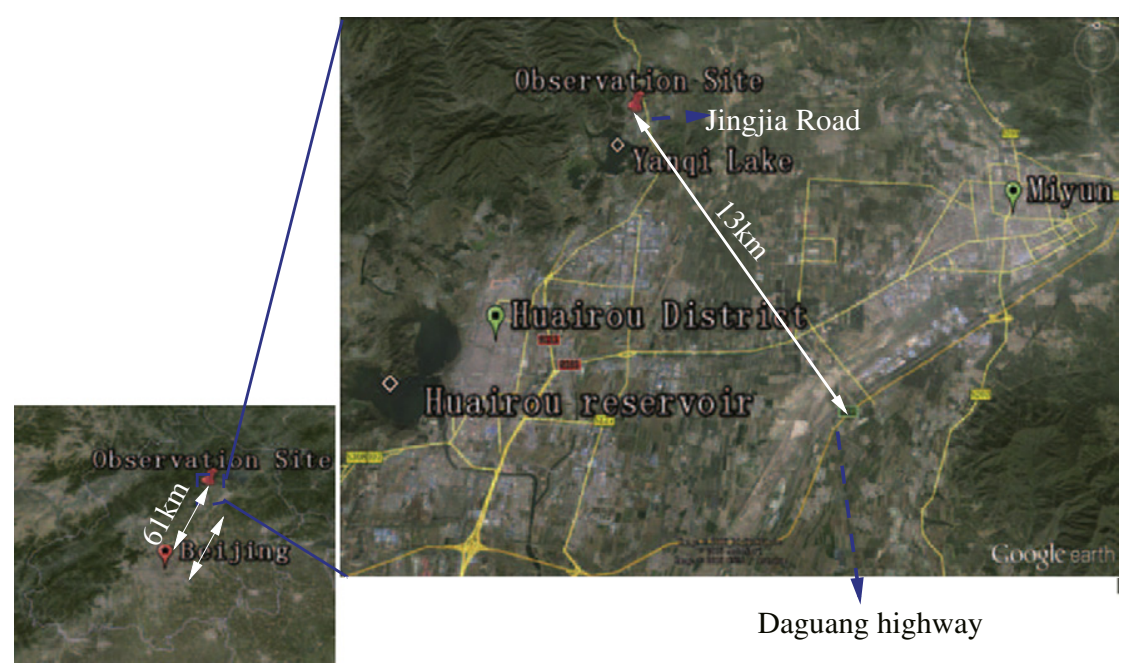

Fig. 2 - Observation site $\left(40.4^{\circ} \mathrm{N}, 116.6^{\circ} \mathrm{E}\right)$ in the Yanqi Lake campus of University of Chinese Academy of Sciences in Huairou district in Beijing. 


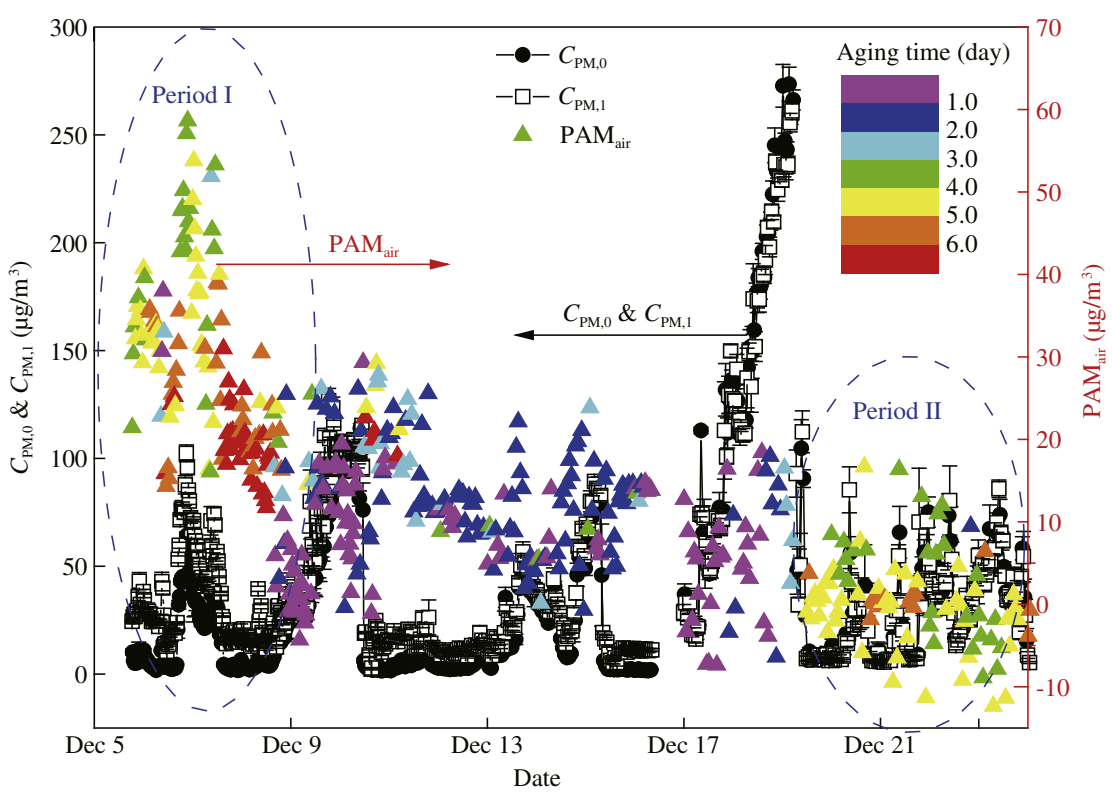

Fig. 3 - Time series of potential aerosol mass (PAM) concentrations at the observation site $\left(40.4^{\circ} \mathrm{N}, 116.6^{\circ} \mathrm{E}\right)$ in $\mathrm{Huairou}$ district in Beijing in the winter of 2014. The solid circles and the open squares are the measured concentrations of aerosol in the outlet of the PAM reactor and the bypass reactor, respectively; the colored triangles are the calculated PAM, with the color indicating the aging time equivalent to atmospheric oxidation. Two representative periods with distinct PAM were chosen for contrastive analysis in this study, named "Period I" and "Period II", respectively.

observation site. The peak was usually $10-20 \mu \mathrm{g} / \mathrm{m}^{3}$ higher than the PAM before or after the morning traffic jam. However, no obvious peaks were observed for the afternoon rush hours.

Besides the PAM, the concentrations of air pollutants are also displayed in Fig. 4. Overall, the concentrations of the pollutants, including $\mathrm{NO}_{2}, \mathrm{SO}_{2}, \mathrm{O}_{3}$, and $\mathrm{PM}_{2.5}$, were higher in Period I than in Period II. In Period I, the peak concentrations of $\mathrm{NO}_{2}$, and $\mathrm{SO}_{2}$ were as high as $100 \mu \mathrm{g} / \mathrm{m}^{3}$, while the peak was at about $200 \mu \mathrm{g} / \mathrm{m}^{3}$ for $\mathrm{PM}_{2.5}$. In Period II, relatively lower concentrations of these pollutants were observed, but the air was still not very clean. The peak concentrations of $\mathrm{NO}_{2}$ and $\mathrm{SO}_{2}$ in Period II were about $50 \mu \mathrm{g} / \mathrm{m}^{3}$, which was half that in Period I, while $\mathrm{O}_{3}$ concentrations in the two periods were similar. Clearly, the change in the PAM was disproportionate to the change in the gas phase pollutants. The difference in PAM indicated different pollution properties in these two periods. In the following sections, we will discuss these in detail by analyzing the relationships between the PAM and other air pollutants, aging time, scenarios of transport and so on.

\subsection{Relationships between the PAM and the concentrations of air pollutants}

In Period I, linear correlations were observed between the PAM and other air pollutants, such as $\mathrm{SO}_{2}, \mathrm{NO}_{2}, \mathrm{CO}, \mathrm{PM}_{2.5}$ and $\mathrm{PM}_{10}$, as shown in Fig. 5. Higher PAMs were detected under higher pollution conditions. From the correlation equation, an intercept of about $17 \mu \mathrm{g} / \mathrm{m}^{3}$ PAM was obtained for all the positively correlated air pollutants, i.e., $\mathrm{SO}_{2}, \mathrm{NO}_{2}, \mathrm{CO}, \mathrm{PM}_{2.5}$ and $\mathrm{PM}_{10}$. This was consistent with the fact that a significant PAM was observed in Period I even under clean atmospheric conditions, when the concentrations of inorganic gas pollutants were low. This result indicated that some precursors for secondary aerosol formation, such as volatile organic compounds (VOCs) from biogenic emissions, contributed to the PAM. The PAM was found to be negatively correlated to ozone. There might be two reasons for this phenomenon. One was that the meteorological conditions usually favored the diffusion of the air pollutants when ozone was high, while the other was that ozone was an indicator of secondary processes in the real atmosphere. The high ozone concentrations in the atmosphere may suggest that oxidation processes in the real atmosphere had already occurred. Hence, aerosol production in the PAM reactor was not favored under high ozone concentration conditions. In Period II, there was no obvious correlation between the PAM and other air pollutants, since the PAM fluctuated around zero.

\subsection{Change trends of PAM with aging time}

The PAM was also found to be dependent on the aging time equivalent to atmospheric oxidation. In period I, we observed an increasing particle formation with increasing aging time up to 3 days, while further aging seemed to decrease the particle mass concentration, as indicated in Fig. 6. This was consistent with other observation data from in situ PAM experiments (Tkacik et al., 2014). The decrease of the aerosol mass was due to the shift from functionalization to fragmentationdominated reaction mechanisms for SOA oxidation in both the newly generated aerosol and the preexisting aerosols. However, the pattern of the change trend of particle production with aging time in Period II was different. An increasing trend was not observed in period II. It seemed that increasing aging time resulted in a slight decrease of particle mass 

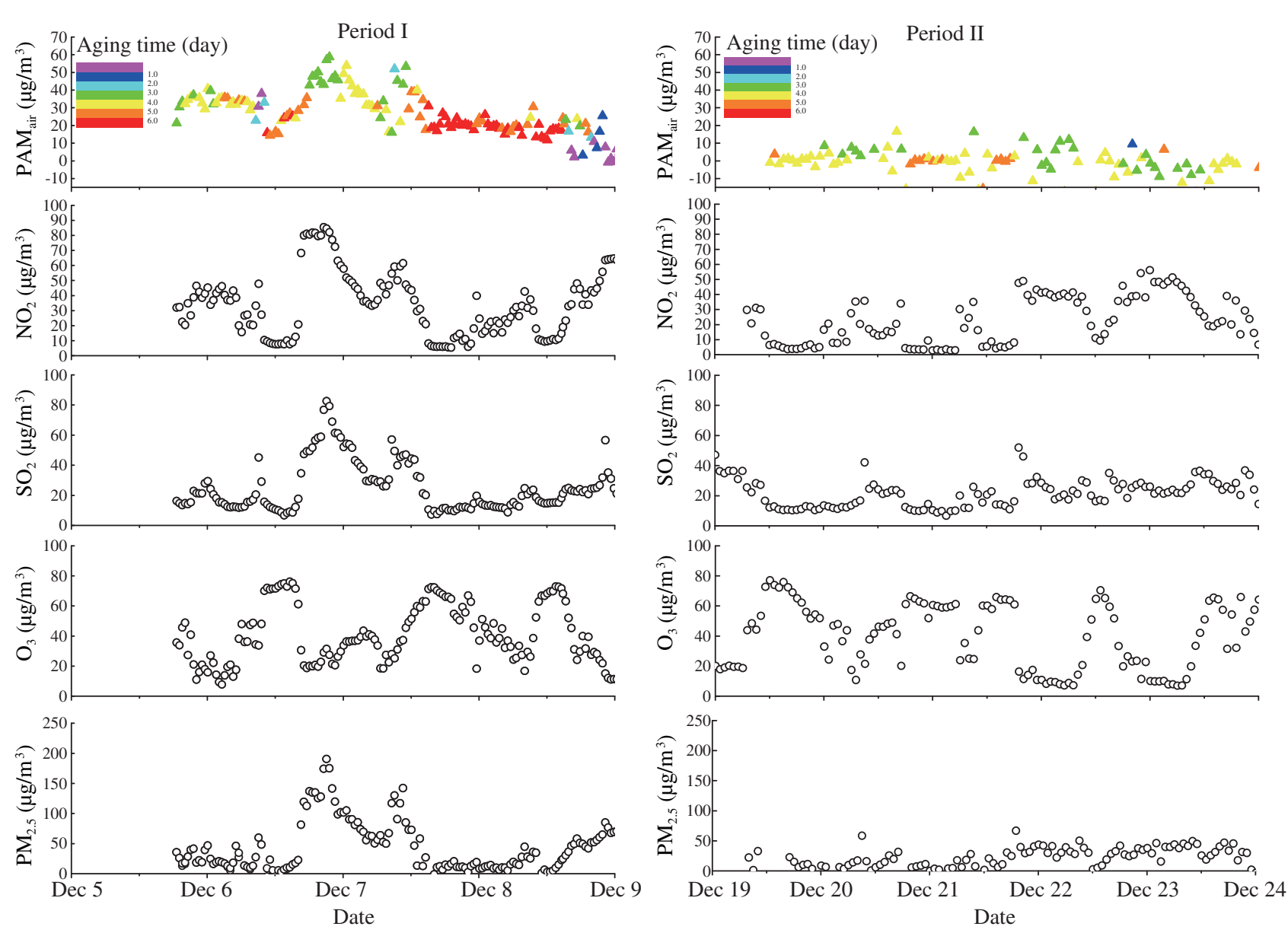

Fig. 4 - Time variation of potential aerosol mass (PAM), $\mathrm{NO}_{2}, \mathrm{SO}_{2}, \mathrm{O}_{3}$, and $\mathrm{PM}_{2.5}$ concentrations during two representative periods at the observation site $\left(40.4^{\circ} \mathrm{N}, 116.6^{\circ} \mathrm{E}\right)$ in Huairou district in Beijing in the winter of 2014. The color of the PAM data points indicates the aging time equivalent to atmospheric oxidation.

concentration beginning at short aging times. This might indicate that the aerosol in Period II was more easily decomposed, and resulted in particle mass loss with additional $\mathrm{OH}$ exposure. It is well known that the oxidation level of the organic aerosol usually increases with aging. Meanwhile, the branching ratio of fragmentation to functionalization increased with the increasing oxidation level. It was found that the branching ratio between fragmentation and functionalization increased dramatically as O/C rose (Donahue et al., 2012; Jimenez et al., 2009; Kroll et al., 2009). Therefore, the phenomenon that aerosol production decreased slightly with increasing aging time from the very beginning might be presumably linked with a higher aging level for the organic aerosol in Period II. We speculate that the organic aerosol fragmented more easily with the additional $\mathrm{OH}$ exposure, and the heterogeneous oxidation of pre-existing particles resulted in more mass loss of the preexisting aerosols in Period II than in Period I.

\subsection{PAM under different scenarios of transport}

The difference in PAM between Period I and Period II indicated different pollution patterns during the two periods. We analyzed the meteorological parameters during the observation period, which were obtained from http://www.weather.com.cn/ weather/101010100.shtml for Huairou station. The temperature and $\mathrm{RH}$ during the two periods were similar. The average temperature was about $-2^{\circ} \mathrm{C}$, usually with a maximum temperature of about $4^{\circ} \mathrm{C}$ in the afternoon and a minimum temperature of about $-7^{\circ} \mathrm{C}$ in the early morning. The average $\mathrm{RH}$ was about $31 \%$, ranging from $10 \%$ to $90 \%$ and inversely related to the temperature. However, since the flow reactors were placed in the room and the temperature were controlled by circulating water, the ambient air sample was actually heated to about $25^{\circ} \mathrm{C}$ in the flow reactors. At the same time, with humid zero air added into the flow reactor, the $\mathrm{RH}$ in the flow reactor ranged between $20 \%-30 \%$. The wind speed in this period was usually below $1 \mathrm{~m} / \mathrm{sec}$, while sometimes high speed wind up to $5 \mathrm{~m} / \mathrm{sec}$ from the north could last for several hours. Wind speed and direction statistics in Period I and Period II are compared and displayed in Fig. 7. In Period I, the wind at the observation site was mainly from east and northwest, while in Period II northwest wind dominated. Wind speed in Period II was also higher than in Period I.

The backward trajectory analyses of the air masses during the two periods are displayed in Fig. 8. The target time was the time point of the peak concentration of background particle concentration in the two periods. During these two periods, 



Fig. 5 - Correlation between the potential aerosol mass (PAM) and other air pollutants in Period I at the observation site $\left(40.4^{\circ} \mathrm{N}\right.$, $116.6^{\circ} \mathrm{E}$ ) in Huairou district in Beijing in the winter of 2014.

air mass was mainly from the north in both cases, but the distance in Period I was shorter than in Period II. More importantly, as the red back trajectory indicates, in the most recent $6 \mathrm{hr}$, air masses were mainly from local sources in Period I. This was different from the other back trajectories in Period I and all the back trajectories in Period II, which corresponded to long distance transport. The backward trajectories were consistent with the results displayed in Figs. 5 and 6. The air mass from local areas in Period I was less aged than that in Period II, and had a higher secondary aerosol formation potential. In Period II, air mass from long-range transport had a low secondary aerosol formation potential, and meanwhile the particles presumably had higher aging level and resulted in a decreasing trend in mass concentration with additional $\mathrm{OH}$ exposure from the very beginning.

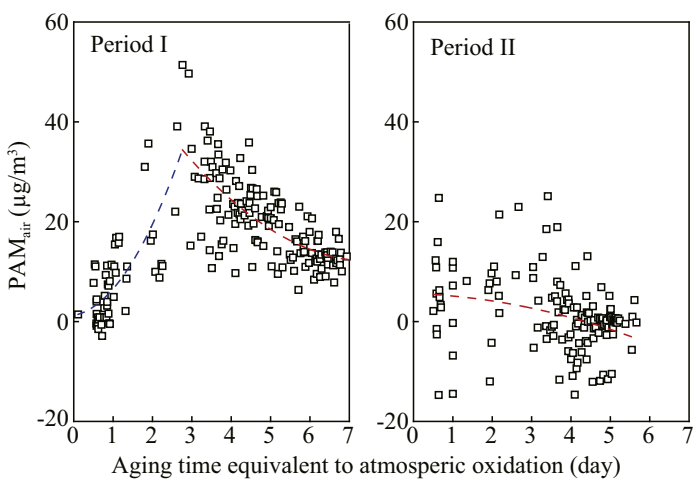

Fig. 6 - Potential aerosol mass (PAM) as a function of aging time equivalent to atmospheric oxidation in Period I and Period II at the observation site $\left(40.4^{\circ} \mathrm{N}, 116.6^{\circ} \mathrm{E}\right)$ in Huairou district in Beijing in the winter of 2014.
The distinct PAMs under different scenarios of transport at the suburban site of Beijing indicated that air masses from local emission and regional transport might have different contributions to the PAM. We suspected that air masses from long distance regional transport, especially those from a relatively clean background area, might have a less important contribution to secondary aerosol compared to local emission during the observation period. High PAM was observed when the surface air mass was mainly controlled by local emissions. In Fig. 5, the PAM correlated well to $\mathrm{SO}_{2}, \mathrm{NO}_{2}$, and $\mathrm{CO}$, which could all be associated to combustion processes. This is consistent with the large contribution of residential heating to the emission of these pollutants in Beijing in the winter (Feng et al., 2014; Zhang et al., 2011; Ji et al., 2014). Ji et al. (2014) attributed the "explosive growth" of fine particles mainly to local emissions under stagnant conditions during the heaviest particulate air-pollution episodes in the winter of Beijing, which was consistent with our experimental results in some respects. The regional transport of particles might be a major reason for the severe haze pollution in Beijing, but the contribution of local emission to secondary aerosol formation was also crucial.

\section{Conclusions}

According to the in situ perturbation experiments in a PAM reactor carried out at a suburban site of Beijing, two periods with very different secondary aerosol formation potential, designated as Period I and Period II, were identified in December 2014. In Period I, the air mass was from local sources. The potential of secondary aerosol formation was high, and was relatively well correlated to the air pollutants, 

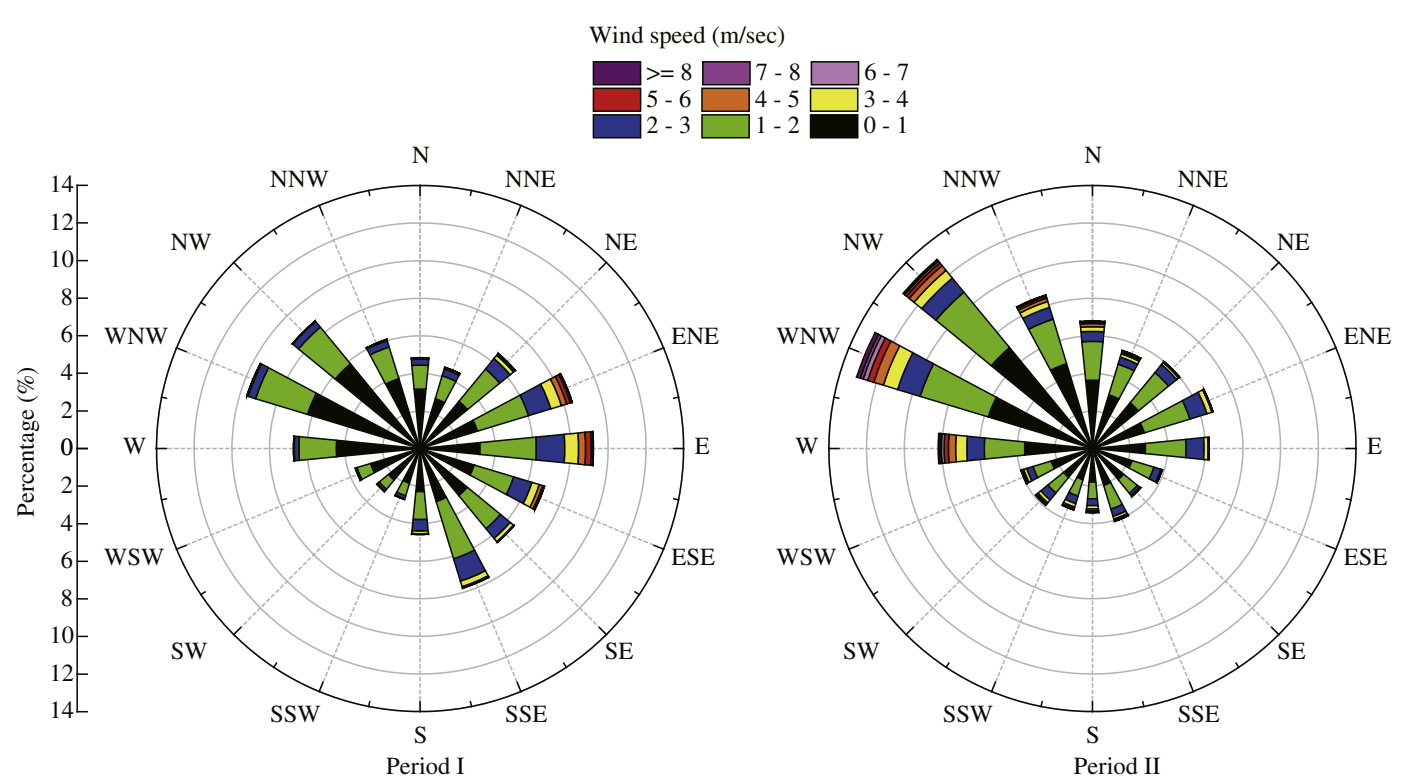

Fig. 7 - Wind speed and direction statistics in Period I and Period II in Huairou district in Beijing in the winter of 2014.

i.e., $\mathrm{SO}_{2}, \mathrm{NO}_{2}, \mathrm{CO}, \mathrm{PM}_{2.5}$ and $\mathrm{PM}_{10}$. A peak concentration of secondary aerosol formation potential was observed with an aging time equivalent to about 3 days of atmospheric oxidation, while secondary aerosol formation became lower with further oxidation due to a shift from functionalization to fragmentation-dominated reaction mechanisms for SOA oxidation. In Period II, the air mass was contributed by long-range transport, with low secondary aerosol formation potential. The secondary aerosol formation potential had no obvious correlation with the air pollutants. Meanwhile, the secondary aerosol formation potential decreased with the increase in aging time equivalent to atmospheric oxidation in Period II, instead of showing a peak as a function of the aging time as in Period I. The air lost its reactivity during the long transport and
NOAA HYSPLIT MODEL

Backward trajectories ending at 1300 UTC 06 Dec 14 GDAS Meteorological Data



Period I
NOAA HYSPLIT MODEL

Backward trajectories ending at 0200 UTC 22 Dec 14 GDAS Meteorological Data

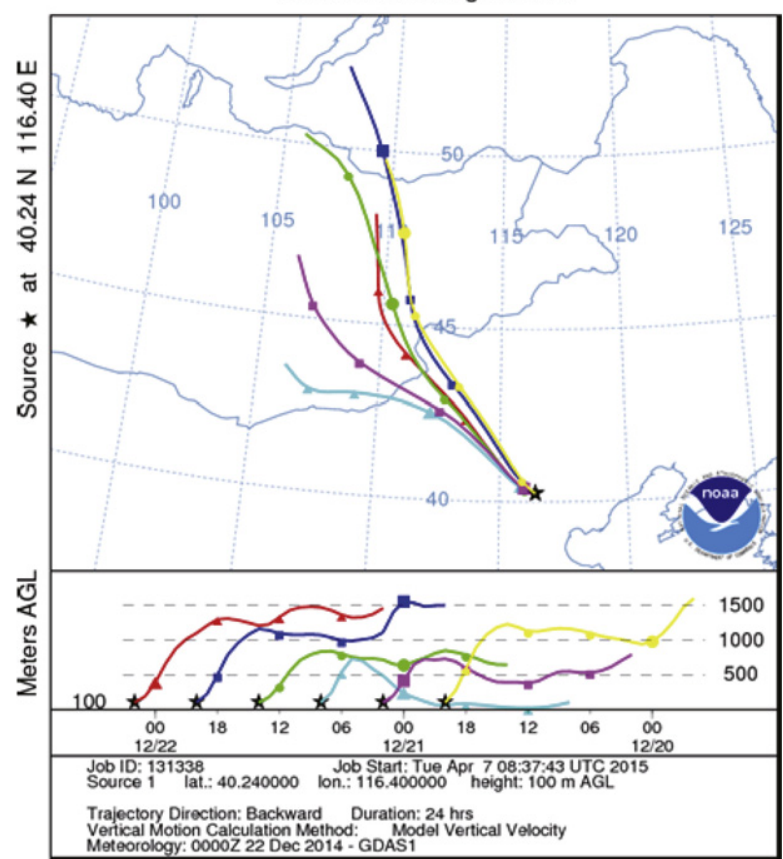

Period II

Fig. 8 - Backward trajectory analysis of the air mass in Period I and Period II at the observation site $\left(40.4^{\circ} \mathrm{N}, 116.6^{\circ} \mathrm{E}\right)$ in $\mathrm{Huairou}$ district in Beijing in the winter of 2014. 
the particles became highly aged, resulting in a low secondary aerosol formation potential. Our experimental results indicated that in situ measurement of the secondary aerosol formation potential could provide important information for evaluating the contributions of local emission and long distance transport to aerosol pollution.

\section{Acknowledgments}

This work was supported by the Key Research Program of Chinese Academy of Sciences (No. KJZD-EW-TZ-G06-01-15), the National Natural Science Foundation of China (No. 21407158), and the Strategic Priority Research Program (B) of the Chinese Academy of Sciences (No. XDB05010300).

\section{R E F E R E N C E S}

Chen, S., Brune, W.H., Lambe, A.T., Davidovits, P., Onasch, T.C., 2013. Modeling organic aerosol from the oxidation of alpha-pinene in a Potential Aerosol Mass (PAM) chamber. Atmos. Chem. Phys. 13, 5017-5031.

Dan, M., Zhuang, G., Li, X., Tao, H., Zhuang, Y., 2004. The characteristics of carbonaceous species and their sources in $\mathrm{PM}_{2.5}$ in Beijing. Atmos. Environ. 38, 3443-3452.

Donahue, N.M., Henry, K.M., Mentel, T.F., Kiendler-Scharr, A., Spindler, C., Bohn, B., et al., 2012. Aging of biogenic secondary organic aerosol via gas-phase $\mathrm{OH}$ radical reactions. Proc. Natl. Acad. Sci. U. S. A. 109, 13503-13508.

Duan, F., He, K., Ma, Y., Jia, Y., Yang, F., Lei, Y., et al., 2005. Characteristics of carbonaceous aerosols in Beijing, China. Chemosphere 60, 355-364.

Farmer, D.K., Jimenez, J.L., 2010. Real-time atmospheric chemistry field instrumentation. Anal. Chem. 82, 7879-7884.

Feng, X., Li, Q., Zhu, Y., Wang, J., Liang, H., Xu, R., 2014. Formation and dominant factors of haze pollution over Beijing and its peripheral areas in winter. Atmos. Pollut. Res. 5, 528-538.

Guo, S., Hu, M., Zamora, M.L., Peng, J.F., Shang, D.J., Zheng, J., et al., 2014. Elucidating severe urban haze formation in China. Proc. Natl. Acad. Sci. U. S. A. 111, 17373-17378.

He, K., Yang, F., Ma, Y., Zhang, Q., Yao, X., Chan, C., et al., 2001. The characteristics of $\mathrm{PM}_{2.5}$ in Beijing, China. Atmos. Environ. 35, 4959-4970.

He, H., Wang, Y., Ma, Q., Ma, J., Chu, B., Ji, D., et al., 2014. Mineral dust and $\mathrm{NO}_{x}$ promote the conversion of $\mathrm{SO}_{2}$ to sulfate in heavy pollution days. Sci. Rep. 4, 04172.

Ji, D., Li, L., Wang, Y., Zhang, J., Cheng, M., Sun, Y., et al., 2014. The heaviest particulate air-pollution episodes occurred in northern China in January, 2013: insights gained from observation. Atmos. Environ. 92, 546-556.

Jiang, J., Zhou, W., Cheng, Z., Wang, S., He, K., Hao, J., 2015. Particulate matter distributions in China during a winter period with frequent pollution episodes (January 2013). Aerosol Air Qual. Res. 15, 494-U157.

Jimenez, J.L., Canagaratna, M.R., Donahue, N.M., Prevot, A.S.H., Zhang, Q., Kroll, J.H., et al., 2009. Evolution of organic aerosols in the atmosphere. Science 326, 1525-1529.

Kang, E., Root, M.J., Toohey, D.W., Brune, W.H., 2007. Introducing the concept of Potential Aerosol Mass (PAM). Atmos. Chem. Phys. 7, 5727-5744.

Kang, E., Toohey, D.W., Brune, W.H., 2011. Dependence of SOA oxidation on organic aerosol mass concentration and $\mathrm{OH}$ exposure: experimental PAM chamber studies. Atmos. Chem. Phys. 11, 1837-1852
Keller, A., Burtscher, H., 2012. A. continuous photo-oxidation flow reactor for a defined measurement of the SOA formation potential of wood burning emissions. J. Aerosol Sci. 49, 9-20.

Kroll, J.H., Smith, J.D., Che, D.L., Kessler, S.H., Worsnop, D.R., Wilson, K.R., 2009. Measurement of fragmentation and functionalization pathways in the heterogeneous oxidation of oxidized organic aerosol. Phys. Chem. Chem. Phys. 11, 8005-8014.

Lambe, A.T., Ahern, A.T., Williams, L.R., Slowik, J.G., Wong, J.P.S., Abbatt, J.P.D., et al., 2011. Characterization of aerosol photooxidation flow reactors: heterogeneous oxidation, secondary organic aerosol formation and cloud condensation nuclei activity measurements. Atmos. Meas. Tech. 4, 445-461.

Lambe, A.T., Onasch, T.B., Croasdale, D.R., Wright, J.P., Martin, A.T., Franklin, J.P., et al., 2012. Transitions from functionalization to fragmentation reactions of laboratory secondary organic aerosol (SOA) generated from the $\mathrm{OH}$ oxidation of alkane precursors. Environ. Sci. Technol. 46, 5430-5437.

Liu, X., Li, J., Qu, Y., Han, T., Hou, L., Gu, J., et al., 2013. Formation and evolution mechanism of regional haze: a case study in the megacity Beijing, China. Atmos. Chem. Phys. 13, 4501-4514.

Ortega, A.M., Day, D.A., Cubison, M.J., Brune, W.H., Bon, D., de Gouw, J.A., et al., 2013. Secondary organic aerosol formation and primary organic aerosol oxidation from biomass-burning smoke in a flow reactor during FLAME-3. Atmos. Chem. Phys. 13, 11551-11571.

Sun, Y., Jiang, Q., Wang, Z., Fu, P., Li, J., Yang, T., Yin, Y., 2014. Investigation of the sources and evolution processes of severe haze pollution in Beijing in January 2013. J. Geophys. Res.- Atmos. 119, 4380-4398.

Tkacik, D.S., Lambe, A.T., Jathar, S., Li, X., Presto, A.A., Zhao, Y.L., et al., 2014. Secondary organic aerosol formation from in-use motor vehicle emissions using a potential aerosol mass reactor. Environ. Sci. Technol. 48, 11235-11242.

Wang, Z., Wang, T., Guo, J., Gao, R., Xue, L., Zhang, J., et al., 2012. Formation of secondary organic carbon and cloud impact on carbonaceous aerosols at Mount Tai, North China. Atmos. Environ. 46, 516-527.

Wang, L., Zhang, N., Liu, Z., Sun, Y., Ji, D., Wang, Y., 2014a. The influence of climate factors, meteorological conditions, and boundary-layer structure on severe haze pollution in the Beijing-Tianjin-Hebei Region during January 2013. Adv. Meteorol. 685971.

Wang, L., Wei, Z., Yang, J., Zhang, Y., Zhang, F., Su, J., et al., 2014 b. The 2013 severe haze over southern Hebei, China: model evaluation, source apportionment, and policy implications. Atmos. Chem. Phys. 14, 3151-3173.

Wang, Y., Yao, L., Wang, L., Liu, Z., Ji, D., Tang, G., et al., 2014c. Mechanism for the formation of the January 2013 heavy haze pollution episode over central and eastern China. Sci. China Earth Sci. 57, 14-25.

Wang, G., Cheng, S., Li, J., Lang, J., Wen, W., Yang, X., et al., 2015. Source apportionment and seasonal variation of $\mathrm{PM}_{2.5}$ carbonaceous aerosol in the Beijing-Tianjin-Hebei Region of China. Environ. Monit. Assess. 187, 4288.

Yang, F., Tan, J., Zhao, Q., Du, Z., He, K., Ma, Y., et al., 2011. Characteristics of $\mathrm{PM}_{2.5}$ speciation in representative megacities and across China. Atmos. Chem. Phys. 11, 5207-5219.

Zhang, J., Ouyang, Z., Miao, H., Wang, X., 2011. Ambient air quality trends and driving factor analysis in Beijing, 1983-2007. J. Environ. Sci. 23, 2019-2028.

Zhao, P., Dong, F., He, D., Zhao, X., Zhang, X., Zhang, W., et al., 2013a. Characteristics of concentrations and chemical compositions for $\mathrm{PM}_{2.5}$ in the region of Beijing, Tianjin, and Hebei, China. Atmos. Chem. Phys. 13, 4631-4644.

Zhao, X., Zhao, P., Xu, J., Meng, W., Pu, W., Dong, F., et al., 2013b. Analysis of a winter regional haze event and its formation 
mechanism in the North China Plain. Atmos. Chem. Phys. 13, 5685-5696.

Zheng, B., Zhang, Q., Zhang, Y., He, K., Wang, K., Zheng, G., et al., 2014. Heterogeneous chemistry: a mechanism missing in current models to explain secondary inorganic aerosol formation during the January 2013 haze episode in North China. Atmos. Chem. Phys. 15, 2031-2049.
Zheng, G., Duan, F., Su, H., Ma, Y., Cheng, Y., Zheng, B., et al., 2015. Exploring the severe winter haze in Beijing: the impact of synoptic weather, regional transport and heterogeneous reactions. Atmos. Chem. Phys. 15, 2969-2983. 